\author{
Jens Andreas Sickor
}

\title{
Das Geständnis
}

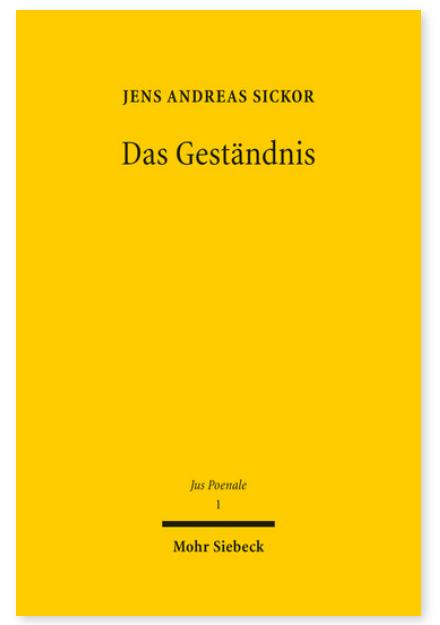

2014. XXII, 582 Seiten. JusPoen 1

ISBN 978-3-16-153394-5

DOI 10.1628/978-3-16-153394-5

eBook PDF 159,00€

ISBN 978-3-16-153113-2

Leinen $159,00 €$
Obwohl in der Praxis von überragender Bedeutung, enthält das Strafprozessrecht keine konkreten Vorgaben zum Umgang mit einem Geständnis des Beschuldigten. Die Rechtsnatur des Geständnisses bestimmt Jens Andreas Sickor deshalb ausgehend von rechtshistorischen und rechtsvergleichenden Betrachtungen sowie unter Rückgriff auf die Prozessstruktur und das Beweisrecht der StPO. Zugleich unterzieht er den Umgang der Strafverfahrenspraxis mit dem Geständnis einer kritischen Betrachtung. Dazu zählen z.B. die Tauglichkeit des Geständnisses als »Wahrheitsgewinnungsmittel«, die - auch durch Strafverfolgungsorgane gesetzten - Ursachen für Falschgeständnisse sowie die Legitimierbarkeit und die Gefahren der strafmildernden Berücksichtigung eines Geständnisses. Besonderes Augenmerk wird auf die Folgen des Verständigungsverfahrens (§ 257c StPO) sowie auf die Bedeutung des Geständnisses in Kronzeugenregelungen gelegt.

Jens Andreas Sickor Geboren 1974; Studium der Rechtswissenschaften an der Technischen Universität Dresden; Wissenschaftlicher Mitarbeiter an der Technischen Universität Dresden; Rechtsreferendar im OLG-Bezirk Bamberg; 2004 Promotion; Wissenschaftlicher Mitarbeiter an der Ruhr-Universität Bochum; WS2012/2013 und SoSe 2013 Vertretung des Lehrstuhls für Strafrecht, Strafprozessrecht und Juristische Zeitgeschichte an der Fernuniversität in Hagen; 2013 Habilitation; WS 2013/2014 Vertretungsprofessor am Lehrstuhl für Strafrecht, Strafprozessrecht, Rechtsphilosophie und Rechtssoziologie an der Ludwig-Maximilians-Universität München.

\section{Jetzt bestellen:}

https://mohrsiebeck.com/buch/das-gestaendnis-9783161533945?no_cache=1

order@mohrsiebeck.com

Telefon: +49 (0)7071-923-17

Telefax: $+49(0) 7071-51104$ 